\begin{tabular}{|c|c|c|c|c|c|}
\hline MUNIBE Antropologia-Arkeologia & $n^{\circ} 69$ & $333-341$ & DONOSTIA & 2018 & ISSN 1132-2217 • elSSN 2172-4555 \\
\hline
\end{tabular}

\title{
Gongora-ko (Nafarroa) Jauregizaharra jauregiaren datazio dendrokronologikoa
}

\author{
Datación dendrocronológica del palacio \\ Jauregizaharra de Gongora (Navarra) \\ Dendrochronological dating of Jauregizaharra \\ palace of Gongora (Navarre)
}

PALABRAS CLAVES: Dendrocronología; Edad Media; Edad Moderna; Navarra; Palacio.

GAKO-HITZAK: Dendrokronologia; Erdi Aroa; Aro Modernoa; Nafarroa; Jauregia.

KEY WORDS: Dendrochronology; Middle Ages; Modern Age; Basque Country; Palace.

Joxexabin LIZEAGA RIKA ${ }^{(1)}$

\section{RESUMEN}

Lan honetan Nafarroako Gongora herriko Jauregizaharraren datazio dendrokrologikoa aurkezten da. Dendrokronologia aldetik hiru erreferentziazko zur-kronologia sortu dira, eta eraikuntzen alde historikotik, Espainiako ipar-erdialdeko aristokrazia leinuen ohiko eraikuntza den jauregiaren eraikuntza faseen datazioa aurkezten da. Alde dendrokronologikoan guztira 242 ametz, erkametz, pinu gorri eta zumarren zurak aztertu dira. Zur hauek XV. mendetik XIX. mende arteko zuhaitz ebaketa datak eman dituzte. Eraikuntzaren aldetik, hasieran defentsarako prestatuak ziren egiturak, inguruko hainbat baliabide ekonomikori erantzuna emateko garatutako jauregia bihurtu zen. Dorre garai oin karratu baten inguruan eraikin itsatsiak egin ziren, lehenik erdiko patio bat eta ondoren inguruan hainbat eraikin erantsiak eraiki ziren bigarren patio bat sortuaz. $\mathrm{XV}$. medea baino lehenagokoa den dorrea da hasierako eraikina, $\mathrm{XV}$. mendearen bukaeran alde batera dorreari eraikin berriak eta patio bat erantsi zitzaizkion. XVI. mendearen hasieran bigarren patio handiago bat erantsi zitzaion. Zuren ebaketa data aintzaz hartuz gero esan daiteke jauregiaren zatirik handiena 1445. urtetik 1510. urte artean egina dela.

\section{LABURPENA}

En este trabajo se presenta la datación dendrocronológica del palacio Jauregizaharra de Gongora (Navarra). Desde el aspecto dendrocronológico se han construido 3 cronologías de referencia, y, desde el punto de vista de la historia de edificios de linajes aristocráticos, se presenta la datación de las fases del palacio. Desde el lado dendrocronológico se han analizado un total de 242 maderas de roble pubescente, quejigo, pino albar y olmo. Se han comparado con cronologías absolutas de la zona. Esta comparación ha dado dataciones de derribo del árbol del siglo XV hasta el XIX. Inicialmente constaba de una torre de base cuadrada. Alrededor de la torre se fueron construyendo diversos edificios hasta crear un primer patio a finales del siglo XV. El siglo XVI se construyó un segundo patio más amplio. Tomando en consideración las dataciones de corte de los árboles se puede decir que la mayor parte del palacio se construyó entre los años 1445 y 1510.

\section{ABSTRACT}

Several dendrochronological studies have been conducted in the Basque Country (Susperregi and Prado, 2000 and 2003; Susperregi, 2004 and 2016; Susperregi et al., 2017; Lizeaga, 2009 and 2010). This paper presents the dates assigned to many wooden structures of the medieval palace of Jauregizaharra, which is located in Gongora (Image 1). Furthermore, absolute chronologies were determined with regard to Pyrenean oaks, Portuguese oaks, Scots pines and elms.

Gongora is a village located in the municipality of Aranguren (Image 2). The sub-Mediterranean climate characterises the area studied. In the surrounding plain, there are forests composed of Quercus faginea, Q. humilis and Q. ilex. In the mountain side, Pinus sylvestris and Fagus sylvatica are the predominant trees. The palace of Gongora was first mentioned in the year 1389.

Table I shows the amount of samples obtained. Wood slices (Image 4) and wood chips pulled out by using a drill (Image 5) were sampled.

Based on the dichotomous keys developed by Sherwin (1988) and Schoch et al. (2017), the gender of botanical species of wood was identified: Quercus sp., Pinus sp. and Ulmus sp.

After being sanded, wood samples were scanned using $2400 \mathrm{dpi}$, and the width of the rings was measured by using the application OSM (Knibbe, 2000) in two opposed radii. False rings, missing rings, cumulative growth, damage to the wood caused by breaking and similar anatomical issues were identified.

Computer applications such as COFECHA (Holmes, 1983) and dpIR (Bunn, 2008; Bunn, 2010) were used to examine statistics on cross-dating. In order to calculate the index of measurements of rings, researches used smoothing splines with $50 \%$ frequency response of 32 years, autoregressive models, logarithms and Tukey's range test (Cook and Kairiukstis, 1990 and Grissino-Mayer, 2001).

\footnotetext{
(1) Nafarroako Unibertsitate Publikoa. Matematika Departamentua. Arteak eraikina, sotoa. Arrosadia Campusa. 31006. Iruñea, Nafarroa. josebasabin.lizeaga@unavarra.es
} 
Three floating chronologies were obtained in total (Table II): Quercus gender (Pyrenean oaks, Portuguese oaks), Pinus gender (several pines) and Ulmus gender (elm). The three chronologies determined in Gongora were cross-dated with absolute chronologies of Quercus sp. in Navarre (Table III).

The reliability of the chronology of Pyrenean oaks and Portuguese oaks is very high. Statistical results obtained from data about chronologies of elms and Pyrenean oaks are also appropriate. Nevertheless, since different species were cross-dated, there is not enough foundation to determine its adequacy. The adequacy of the chronogoly of pines is moderate.

A piece of wood from the oldest part of Jauregizaharra was sampled (Image 6). It has 45 growth rings and cross-dating was impossible. Based on structural elements, the tower of Jauregizaharra is prior to the building phase in 1445.

Eight frames from the ground floor in enclosure 2 (Image 3) date from 1445-1446, four of which were made from the same tree, and four bays date from 1487-1488 (Image 7). Furthermore, the only bay from the ceiling of the ground floor in enclosure 3 dates back to $1487-1488$ as well. Wood in enclosure 6A, both from the first floor and the ceiling date from 1487-1488.

The last time wood was cut in enclosure 15 was in 1490-1491. Wood in enclosure 15 is very different from the rest.

The date of the felling of the wood in enclosure 5, two pieces of wood in enclosure 4 (Pyrenean oak and Portuguese oak) and wood in enclosure 11 date from 1499-1500.

In enclosure 13, the wood of seven bays and the wood of the bar of the main door in enclosure 10 were cut in 1510-1511.

In the years 1563-1564, frames from the first floor of closure 3 were cut. An elm located between enclosures 16 and 14 dates back to $1566-$ 1567. Wood in enclosure 16 dates from 1583-1584.

Nine samples from enclosure 12 date from 1588.

The door head from enclosure 9, the only board found in enclosure 7 and three bays found in enclosure $6 \mathrm{~B}$ are made of wood from the first quarter of the 17 th century.

8 boards from the ceiling, window frames from the eastside, the door frame from enclosure $6 \mathrm{~A}$ and a corbel from enclosure 13 date from the end of the 18th century and the beginning of the 19th century.

The dates provided refer to the felling of the tree. The stone building jointed by wood may be prior or subsequent, since they were used to renovate a building, in the first place. And, in the second place, because wood had two or more purposes. In the case of Jauregizaharra, since 242 pieces of wood were analysed, it is believed that the accuracy of the research data obtained is considerable.

Only after research on other palaces is conducted will the dates determined in Jauregizaharra be able to spread rapidly.

\section{SARRERA}

Gongora eta inguruak historikoki giza jarduera aberatsa izan duen lekua da, eta, ikerketa dendrokronologikoak izan dira, besteak beste, eraikuntzak datatzeko eta bertako populazioen zuraren erabileraren portaera ezagutzeko baliabideetako bat. Horren haritik, eraikuntza zaharrak zur laginen gordailu izan dira, eta honekin batera antzinako basoen ezagutza eta zur eraztun kronologia luzeak sortzeko ezin bestekoak. Azken hamarkadetan, Euskal Herrian, hainbat azterketa dendrokronologikoen garapena eman da (Susperregi eta Prado, 2000 eta 2003; Susperregi, 2004 eta 2016; Susperregi et al, 2017; Lizeaga, 2009 eta 2010). Euskal herriaren isurialde mediterraneorako dugun haritz-erkametz-ametz eraztunen kronologietako bat XIII. mendean hasi eta XXI. mende artekoa da. Egia da, hastapeneko kronologia Lokizko haritz zaharrekin lortutakoa izan dela, hala ere, Gongorako datazio honek aurrekoarekin bateragarria den ametz-kronologia (edo erkametz) berri bat egitea baimendu digu. Gongorako Jauregizaharra (Irudia 1) benetan aberatsa suertatu da, ametzak ez ezik pinu zura eta zumar zura ere baditu.

Interesgarria da Nafarroan eta Espainiako iparraldean hain ugariak diren erdi aroko jauregien datazioa baieztatzea hain zehatza den dendrokronologia zientziatik. Ez hori bakarrik, zaila da dendroarkeologiak eman diezagukeen zehaztasuna beste bide batzuetatik lortzea. Gainera, dendrokronologiak eraikuntzaren atal desberdinen datazioa emateko ahalmena du. Artikulu honetan Jauregizaharran egin den dendroarkeologiko azterketaren emaitzak aurkeztuko dira. Eraikuntzaren historia ulertzeko asmoz, 2008. urtetik aurrera jauregiko zonalde guztietako zurak lagindu dira.

\section{KOKAPENA}

Aranguren udalerriko herrigune bat da Gongora, Iruñetik ekialdera $11 \mathrm{~km}$-tara kokatzen delarik (Irudia 2). Urteko batez besteko tenperatura $13,2^{\circ}$-koa da eta prezipitazioa $721 \mathrm{~mm}$ ingurukoa (Noaingo datuak), hots, klima submediterraniarrak ezaugarritzen du azterketa eremua. Ikuspuntu biogeografiko batetik Gongora inguruko lautadan erkametzez (Quercus faginea), ametzez ( $Q$. humilis) eta artez ( $Q$. ilex) osaturiko basoak gailentzen dira. Arangureneko mendilerroan aldiz, pinu gorriak (Pinus sylvestris) eta pagoak (Fagus sylvatica) hartuko dute protagonismoa.

Gaur egun herrian ez da inor bizi eta zutik diraute 5 eraikinek, horietako bat eliza delarik. Alde historikoan, aurkitu dugun Gongora herriaren lehen aipamena 1368koa da, honen ostean 1389. urtean Gongorako jauregiaren lehen aipamena dugu.

\section{METODOAK}

\subsection{Laginen bilketa eta prestaketa}

Laginketaren estrategia nagusia ahalik eta zur gehien biltzea izan zen, honen haritik, bildutako zur laginek, posible izanez gero, gutxienez 50 hazkuntza-eraztun izan behar zuten, eta zer esanik ez mozte garaiko azken eraztuna ere bai (Cook eta Kairiukstis, 1990). Lekuz kanpo zeuden hagei, motozerraz, leku aproposenean xerra bat moztu zitzaien laborategian aztertzeko. Ordea, eraikinean artean erabilgarri jarraitzen zuten haga eta zurei, barnetik $9 \mathrm{~mm}$-ko diametroa duen daratulu baten bidez eraztunen lekuko bat (ziri bat) atera zitzaien, ondoren laborategian aztertzeko prestaketak eginez. Jauregiak dituen zurak horizontalak dira, berti- 


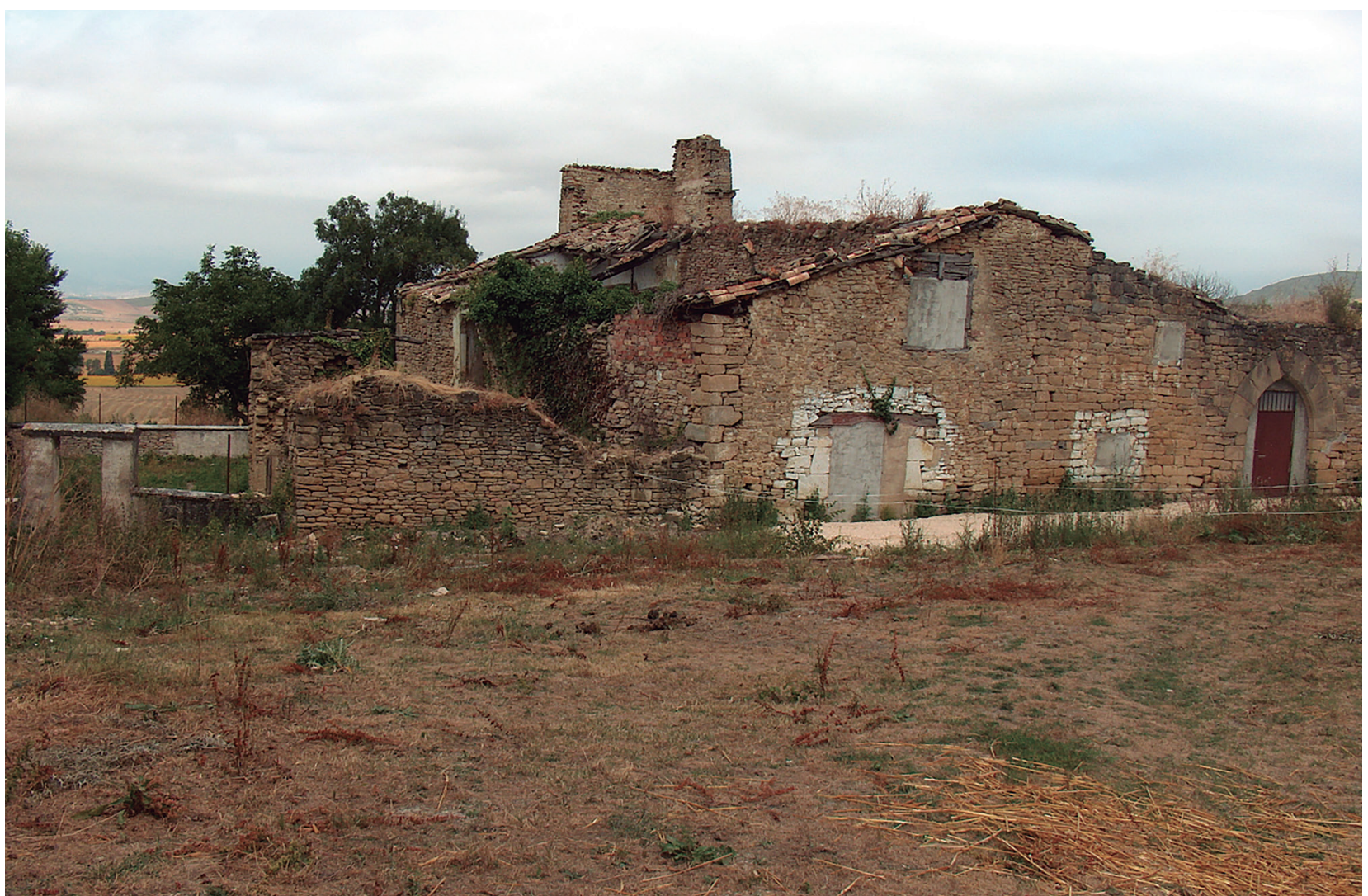

Irudia 1: Gongorako Jauregizaharra 2008. urtean. Ekialdetik begiratuta / The Jauregizaharra palace of Gongora. East view.

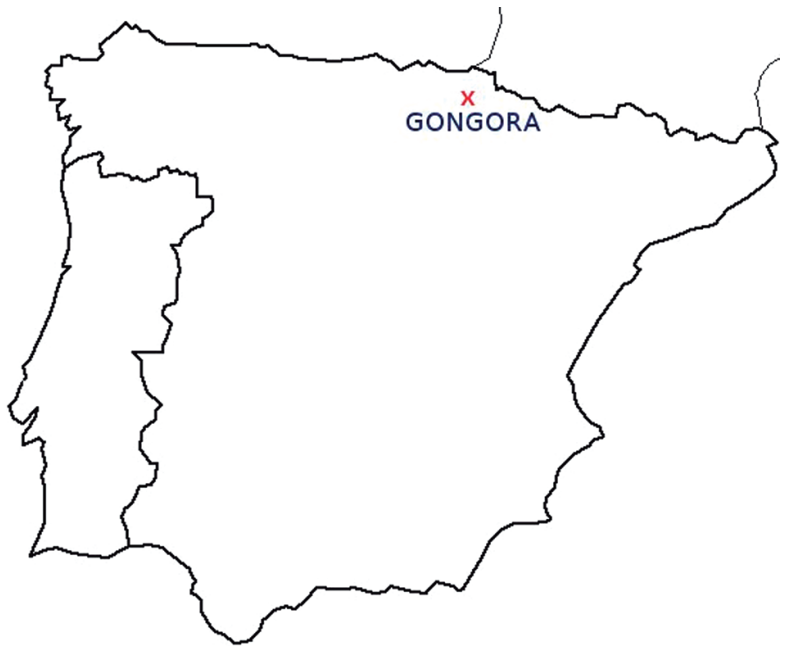

Irudia 2: Gongoraren kokapena / Location of Gongora.

kalik ez dugu aurkitu, hauen artean frontalak (nagusienak, solairuak eratzen dituztenak), soliboak (frontal artekoak), zapatak (pareta gaienean etzanak, paretarekiko paralelo), kuartoiak (solibo arteko zur txikiagoak), leiho eta ate markoak, gailurrak (teilatuaren hegia), tiranteak (teilatupeko zurezko triangeluaren oinarria) eta latak (teila azpiko ohola) izan dira.
1 eta 2 barrutietan (Irudia 3) daratulua erabili da, gainontzekoetan eskuz edo motozerraz enbor xerrak moztu ziren. $\mathbf{4}$. barrutian eta $\mathbf{1 6}$. barrutian zur gehienak galduak edo langileek lekuz aldatuak izan ziren. Honela, I Taulan ikus daiteke barruti bakoitzean hartutako lagin kopurua.

\begin{tabular}{|c|c|c|c|}
\hline Barrutia & Zur kopurua & Barrutia & Zur kopurua \\
\hline 01 & 3 & 11 & 1 \\
\hline 02 & 19 & 12 & 11 \\
\hline 03 & 4 & 13 & 12 \\
\hline 04 & 3 & 14 & 4 \\
\hline 05 & 9 & 15 & 7 \\
\hline 06 & 13 & 16 & 0 \\
\hline 07 & 1 & 17 & 1 \\
\hline 08 & 0 & Beste & 4 \\
\hline 09 & 1 & Testuingururik gabe & 142 \\
\hline 10 & 2 & Guztira & $\mathbf{2 3 7}$ \\
\hline
\end{tabular}

Taula I: Lagindutako zur kopuruak barrutiko / Number of woods sampled by zones. 


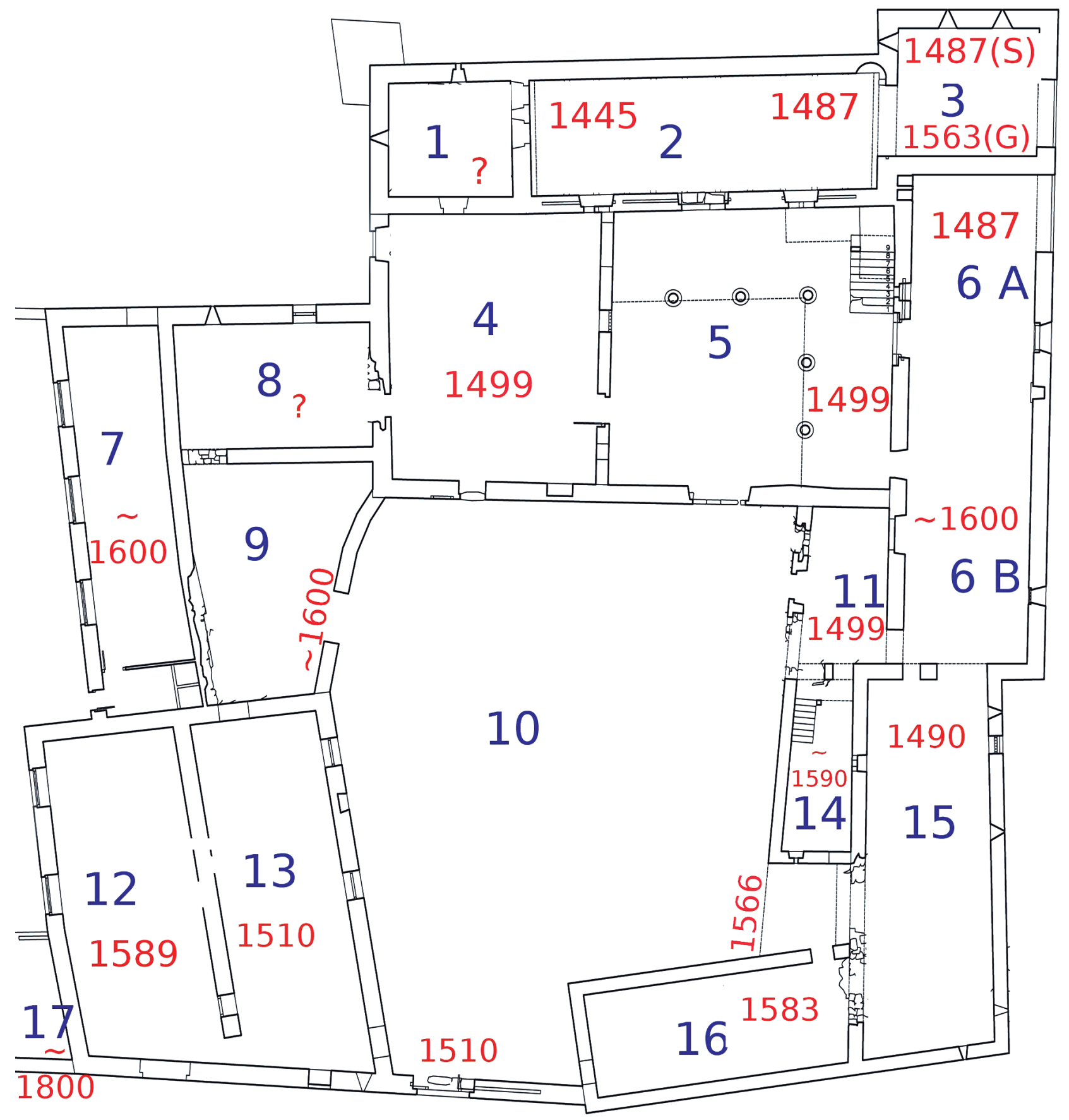

Irudia 3: Jauregizaharraren planoa. Luis Alberdi Sudupek Aranzadi Zientzi Elkartearentzat egina / Plane of Jauregizaharra. Made by Luis Alberdi Sudupe for Aranzadi Zientzi Elkartea. 
Lortutako xerrak (Irudia 4) eta daratuluaz ateratako ziriei (Irudia 5) argazki digitalak egin zitzaizkien.

Laborategian, laginak airean lehortu ziren, ziriak ziri-ohetan gomaz itsatsi eta leuntasuna handiagotuaz hainbat lixa paperez lixatuak izan ziren, ondorioz, ebaketa zeharreko zur zelulak eta zur egiturak agerian utziaz. Mikroskopio behaketa bidez, inguruan erreferentzia gisa hartu ziren zuhaitz ezagunen laginak hartuaz, eta, Sherwin (1988) eta Schoch et alt. (2017) garatutako giltzak erabiliaz, zur espezie botanikoak genero mailan identifikatuak izan ziren. Gongorako jauregia egiteko erabili diren taxak, batetik ametza, erkametza ala haritza (Quercus sp.), bestetik, pinua (Pinus sp.) eta azkenik zumarra (Ulmus sp.) izan dira. Gaur egun, inguruan naturalki Quercus generoko $Q$. humilis eta $Q$. faginea, Pinus generoko $P$. sylvestis eta Ulmus generoko Ulmus minor hazi arren, ezin da baztertu Gongora herritik urrutiago dauden lekuetatik bertakoak ez diren zuhaitzen zurak ekarri izana.

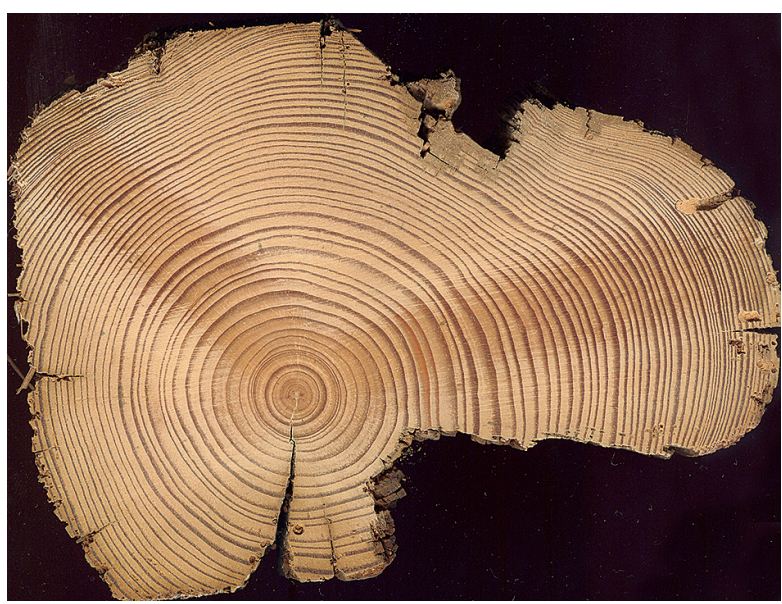

Irudia 4: Enbor xerra. Pinu zura. Bobeda egiteko prestatua / Trunk slice. Pine. Prepared to make boveda.

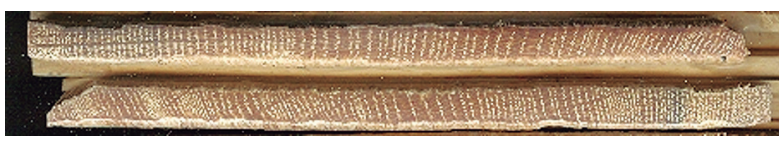

Irudia 5: Daratuluaz ateratako bi ziri lixatuak / Two sanding drilled cores.

\subsection{Datazio gurutzatua}

Lehenik, zur lagina 2400 dpi (dots per inch, edo, 945 puntu/cm) bereizmena erabiliaz eskaneatuak izan ziren, eta OSM (Knibbe, 2000) aplikazioa erabiliaz eraztunen zabalera neurtu zen. Lagina motozerraz ebakitako zilindro (enbor-xerra) bat denean, zilindroaren oinarri den zirkuluan bi aurkako erradio markatu ondoren, erradioetan zehar hazkunde eraztunen zabalera neurtu zen, honela, zilindro bakoitzeko bi eraztun zabalerekin bi zenbaki segida lortu ziren. Lagina daratuluaz lortutako ziria denean, zur bakoitzeko bi erradio desberdinetan zulatuaz bi ziri lortu ziren. Bigarrenik, bai ikusmenaz eta baita ordenagailuz sortutako irudien azterketaz eraztun faltsuak, eraztun galduak, hazkunde pilatuak, hausturek sortutako zuraren kalteak eta antzeko arazo anatomikoak identifikatu ziren. Zur arruntaren eraldaketa hauek guztiak datazio gurutzatuetan baztertuak izan ziren. Hirugarrenik, zur unitate bakoitzeko bi denbora segiden eraztun bakoitzaren batez bestekoa lortu zen, honela, zur unitateko eraztun zabalera segida bakarra erdietsiaz.

Ondoren laginak binaka, bata besteekin, datatzen ahalegindu zen, horretarako, COFECHA (Holmes, 1983) eta dpIR (Bunn, 2008; Bunn, 2010) izeneko aplikazio informatikoak erabili ziren datazioen estatistikak aztertzeko. Denbora segiden ezaugarriak, dataketa gurutzatuak hobetzeko asmoz, neurtutako eraztun zabalerak, \%50eko erantzuna duen eta 32 urteko ibilbidea duen spline kubiko lausotuekin estandarizatuak izan ziren. Iraunkortasuna eredu autoerregresioen bidez ezabatua izan zen. Ondoren segida bakoitza logaritmo bidez eraldatua (Grissino-Mayer, 2001) izan zen. Azkenik, ongi elkar datatzen zuten eraztunen neurri indexatu guztiekin Tukey-ren batez besteko sendoa (Cook eta Kairiukstis, 1990) kalkulatu zen. Aldez aurretik azkeneko hamarkadetan artikuluaren egileak garatu duen EGARANA izeneko erreferentziazko eraztun kronologiaren segidaren (kronologia maisua deituko duguna) aurka datazio gurutzatuak egin ziren. Kronologia maisuaren aurka egin ziren azterketetan maisua eta laginaren 20 urteko segmentuak alderatu ziren eta segmentu hauei 10 urte gehituaz berriro alderatuak. Arau orokor gisa gutxienez \%99ko alde bateko konfiantza mailako korrelazioa erakusten ez zuten segmentuak, edo sistematikoki segmentutik kanpo datatzen zirenak, sistematikoki ikusmenez birberraztertuak izan ziren arazoa identifikatu eta ebazteko asmoz. Laginak onartuak izaten ziren 20 urteko segmentu guztiak edo gehienak \%99ko konfiantza mailatik gorako korrelazioa aurkezten bazuten, eta ikusmenez datazio gurutzatua egokitzat jotzen bazen.

Ondoren, kronologien eraikuntza bideratu zen, horretarako, espezie bereko zur desberdinen datazio gurutzatuan oinarrituz hiru kronologia sortu ziren, lehena ametz-erkametz kronologia, bigarrena pinu kronologia eta hirugarrena zumar kronologia. Hau guztiaren emaitza hiru kronologia flotagarri (egutegi datarik gabeko barne datazio egokia duen kronologia) izan dira.

Eta azkenik, hiru kronologia hauek 1113. urtetik 1993. urtera doan EGARANA izeneko maisu kronologiaren aurka aztertu ziren. Kronologia flotagarrien datazioa onartzeko 50 urteko segmentu gehienen korrelazio koefizientearen konfiantza maila \%99 baino handiagoa izan behar zuen

\subsection{Bukaerako kronologiak eta kanpo azken eraztuna}

Gongorako ametz-erkametz, pinu eta zumar kronologia flotagarriak egutegian datatuak izan ziren EGARANA maisu kronologiaren aurka aztertuaz. COFECHA eta 
dpIR aplikazioen bidez, 50 urteko segmentuak 25naka periodo osoan zehar mugituaz maisu kronologiaren aurka datazio gurutzatua baieztatu zen, zeinetan, estatistikoki eta ikusmenaz korrelazio egokiak jaso ziren. Ondoren kronologia flotagarrien datak eguneratuak izan ziren data zehatzak agerian ezartzeko asmoz.

Kanporengo eraztuna identifikatzeko arazo handiak izan dira, zur gehienak azken 80 urtetan utzitako eraikuntza batean aurkituak izan direnez, gehien kaltetu diren zuren eraztunak kanpokoak izan dira. Honez gain, zurgizena da naturalki pipiak jaten duen zuraren aldea eta horregatik hain garrantzitsua den zurgizena maiz galdua zegoen. Hala ere, kanpoko azken eraztuna kontu handiz birberraztertua izan da azken hazkuntza urtea aurkitzeko asmoz. Ziri eta xerren argazkiak, eta, landa koadernoko apunteak ongi aztertuak izan dira, enbor azala, zurgizena, azken eraztuna eta azken eraztunaren udaberriko zura eta udako zuren aztarnarik zegoen ala ez ebazteko. Lehen eraztuna (zilindroa hobeto esanez) ez zen neurtu eta azken eraztuna ere ez, ez baitago jakiterik osorik garatua izan zen ala bere hazkundea bukatu aurretik zapuztua izan zen.

\section{EMAITZAK}

\subsection{Kronologiak}

Guztira hiru kronologia flotagarri lortu dira (Taula II). Kronologia hauek egiteko erabili diren zuren espeziea ezin izan da ezaugarri anatomikoak erabiliaz zehaztu, horrela, genero mailan geratu gara zuren identifikazioan, hala nola, Quercus generoa (ametza, erkametza), Pinus generoa (hainbat pinu) eta Ulmus generoa (zumarrak).

Kronologia hauen datazioen egokitzapenaren inguruan esan daiteke ametz-erkametzen kronologiaren fidagarritasuna oso handia dela. Zumarren eta ametzen

\begin{tabular}{|c|c|c|c|c|}
\hline Generoa & $\begin{array}{c}\text { Zur } \\
\text { kopurua }\end{array}$ & $\begin{array}{c}\text { Datatutako } \\
\text { zur kopurua }\end{array}$ & $\begin{array}{c}\text { Hasiera } \\
\text { data }\end{array}$ & $\begin{array}{c}\text { Bukaera } \\
\text { data }\end{array}$ \\
\hline $\begin{array}{c}\text { Quercus } \\
\text { (ametza-erka- } \\
\text { metza) }\end{array}$ & 175 & 141 & 1212 & 1802 \\
\hline Ulmus (zumarra) & 22 & 18 & 1468 & 1566 \\
\hline Pinus (pinua) & 35 & 32 & 1316 & 1518 \\
\hline
\end{tabular}

Taula II: Zur kopuruak, lehen urtea eta azken urtea / Number of woods, first year and last year. arteko kronologien arteko emaitzak ere oso egokiak dira, baina, espezie desberdinen arteko datazioa izanik ez dago nahiko eskarmentu egokitasuna zenbatekoa den zehazteko.

Pinuen kronologiaren datazioaren egokitasuna ertaina da, zalantzazkoa dela esan daiteke. Dena dela jauregian erabili diren beste zurek iradokitzen dutenarekin erabat koherentea da.

Datazio gurutzatuak ezagutu asmoz, Gongorako hiru kronologiak EGARANA kronologia, eta elkarren artean alderatu ziren (Taula III).

\subsection{Eraikuntza faseak}

\subsubsection{Dorre zaharraren fasea}

Dorrearen zatirik zaharrenean hiru zur daude oraindik, beheko ate tapiatuan zur ateburu bat, bigarren solairuko ate tapiatuan beste ateburu bat eta bigarren solairuko leiho tapiatuko zurburua beste bat (Irudia 6). Hauetatik bakarra lagindu da, lehen solairuko ateko ateburua alegia. Zur honek, soilik, 45 hazkunde eraztun aurkeztu ditu eta datazio gurutzatua ezinezkoa izan da. Oraingoz eta falta diren bi zurak lagindu ezean ezin dugu dorrearen zati zaharrenaren datarik eman.

Lehen solairutik gora, dorrea ziurrenik 1445. urtean aldatu zen, solairuen altura handitu eta beheko solairu berriaren garaiera handitu zen, aurreko solairu eta erdi hartzen duelarik. Izan ere, 1445ean alboan erantsirik eraiki zenak dorreko lehen solairuko atearen garaieraren
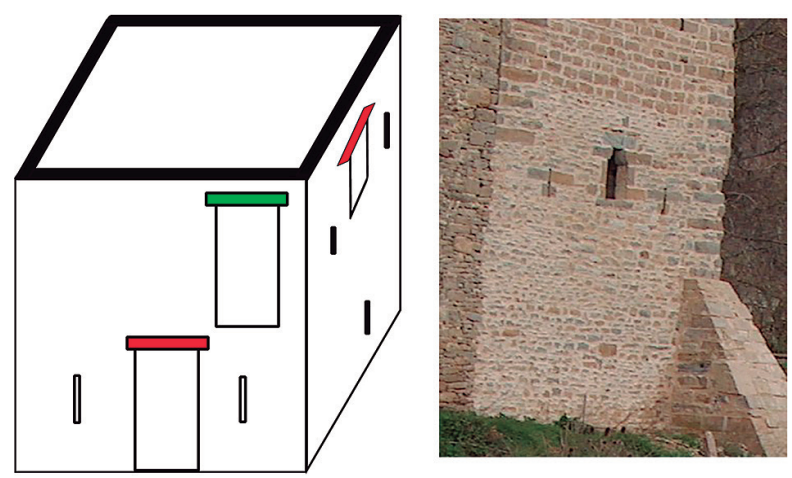

Irudia 6: Gongorako jauregiko alderik zaharrena. Berdez lagindu den zura. Gorriz lagintzeke daudenak. / The oldest part of palace. Wood sampled in green. Wood not sampled in red.

\begin{tabular}{|c|c|c|c|c|c|c|c|}
\hline Kronologiak & Generoa & Ibilbidea & Zur kopurua & $\begin{array}{c}\text { Batez besteko } \\
\text { korrelazioa }\end{array}$ & $\begin{array}{c}\text { Batez besteko } \\
\text { sentikortasuna }\end{array}$ & $\begin{array}{c}\text { Maisu krono- } \\
\text { logia }\end{array}$ & Korrelazioa \\
\hline GONGAMETZ & Quercus & $\begin{array}{c}1212 \\
1802\end{array}$ & 141 & 0,5668 & 0,2066 & EGARANA & $\begin{array}{c}0,54 \\
(591)\end{array}$ \\
\hline GONGPINU & Pinus & $\begin{array}{l}1316 \\
1518\end{array}$ & 32 & 0,5392 & 0,2506 & GONGAMETZ & $\begin{array}{c}0,33 \\
(208)\end{array}$ \\
\hline GONGZUMAR & Ulmus & $\begin{array}{l}1468 \\
1566\end{array}$ & 18 & 0,5062 & 0,2679 & GONGAMETZ & $\begin{array}{c}0,44 \\
(98)\end{array}$ \\
\hline
\end{tabular}

Taula III: Gongorako kronologiak / Gongora's chronologies. 
erdialdean bat egiten dute. Ziurrenik, urte horretan atea harriz itxi zen. 1445.eko fasea baino lehenagokoa da dorrea. Esan daiteke beraz, XV. mendea baino lehenagokoa dela dorre garaia. 3. Irudiko 1 barrutiko zurak dira.

\subsection{2. $1445-1446$ ko fasea}

Dorre zaharrean Iruñera begira jarriz gero eskubitara dagoen hegaleko (3. Irudiko 2 barrutian) beheko solairuan 12 frontal daude lehen solairua eusten. Hauetatik 8 frontal 1445-46. urtean datatu dira, kontuan hartu horietako 4 zuhaitz beretik egindakoak direla (Irudia 7). Ordea, bigarrena eta eskuinetako azken hirurak 42 urte beranduagokoak dira. Hainbat irudi eratzen dituzten, zurezko mentsulen gainean daude 12 frontalak. Urte honetako edo inguruko urtetako hagarik ez dugu beste inon aurkitu, 8 solibo horietaz gaien ez dago garai honetako beste zurik. Izan baziren galdu dira.

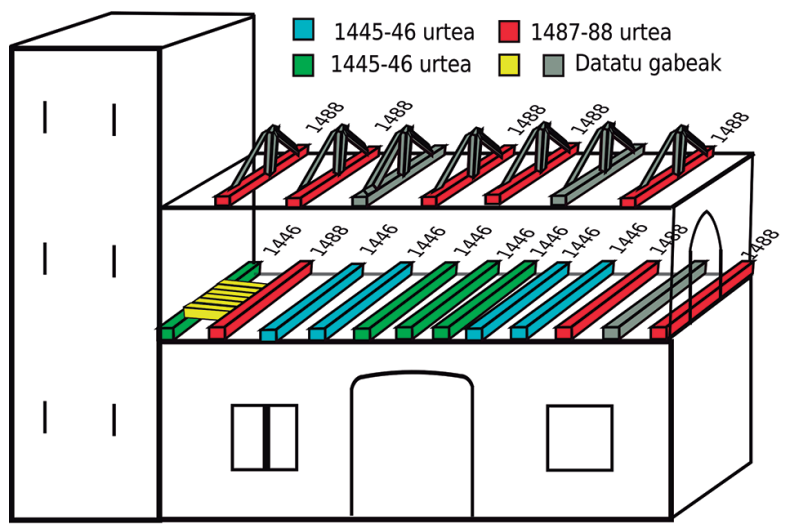

Irudia 7: Dorrearen alboko eraikina / The right side of the tower.

Gainera, solibo hauen kokapenak dorre zaharreko goiko atea itxiarazi zuen eta ziurrenik dorre zahar barruko egitura aldatua izan zen, beheko solairuaren garaiera handituaz eta lehen solairua egin zen eranskinaren parean jarraraziz. Aieru gisa urte hauetan harriz itxi ziren dorre zaharraren beheko atea eta lehen solairukoa.

\subsection{3. $1487-1488$ fasea}

1445-46 urteetatik 1487-88 urte bitarteko zurik ez da aurkitu. Bitako bat, lanak geldirik egon ziren, ala, orain ez dagoen eraikinen bat kendu eta berria egin zen. Lehen hipotesiak aukera gehien dituela uste da, zaila baita hain urte gutxitako zurak, artean erabilgarriak direnak botatzea.

Lehenik, fase honetan, 3. Irudiko 2 barrutian beheko solairuko sabaian lau solibo jarri ziren, lehena dorrearen ondoan bigarrena izango dena. Solibo honek perpendikularki ostiko itxurako 10 zur dorrearen hormaren aurka jarriak ditu. Aieru gisa dorrearen hormarekin arazoren bat izan eta dorrearen pareta indartzeko asmoz egindako lana dela uste da. Beste hirurak beste aldean daude eta horietatik bat ezin izan da datatu (Irudia 7). Zur hauek zurezko mentsula landuen gainean daude. Hala ere dorre zaharrean ez dugu fase honetako zurik aurkitu.

Bigarrenez, planoan 3 izendatu (Irudia 3) den gelaren behe solairuko sabaian aurkitu den solibo bakarraren azken data ere fase honetakoa da.

Hirugarrenez, planoan 6A barrutiko zurak, bai lehen solairukoak eta baita sabaikoak era fase honetakoak dira.

\subsubsection{0-91 fasea}

Planoan 15 zenbakiarekin izendatu den barrutian lagindu diren bost zuretako batek ebaketa azken urtea aurkezten du eta 1490-91koa da. Beste bi zur ezin izan dira elkar datatu eta beste biek azken urtea ez aurkeztu arren aipatutako datekin koherentzia handia dute.

Eraikin honetako zurak oso bereziak dira ez dute Jauregizaharraren beste zuren antzik, hauek elkar lotzeko hainbat miru buztan moduko lotura guneak dituzte. Hormetan zapatak ditu eta bai hauek eta baita ere frontal guztiak miru buztan erako loturez egitura bakar bat eratzen dute. Ez da Jauregizaharrean antzeko beste zur egiturarik ageri, honek pentsa arazten digu beste egiturak eta hau beranduago elkartuak izan zirela.

\subsubsection{9-1500 fasea}

Lehenik, Gongorako Jauregizaharreko patio txikiaren (5 barrutia) zuren ebaketa data urte hauetakoa da. Hemengo zurak pinuak dira eta terraza tankerako patioa eratzen dute. Zur hauek landuak daude, alde batetik bi solibo artean bobeda edo ganga egiteko koska dute eta mutur bat irudiz hornitua dute. Guztira 23 zur bildu dira eta horietatik 9 datatu izan ahal dira. Patio honetan lehen solairuko frontalak ditugu. Hauek frontal arteko gangak egiteko koska dutenak dira. Gainera, badaude lehen solairuko sabaiko soliboak, teilatua luzatzeko direnak, hauek zurginak landuak dira irudi geometrikoak dituztenak alegia.

Bigarrenez, 4 barrutiko zurgizenik gabeko bi zurek 1475 eta 1472ko azken eraztuna dakarte, estrapolazioz eta egituraz 5 barrutiaren antza duenez 1499ko faseari dagokiola uste da. Ordea, zur hauek ametz-erkametzak dira.

11 barrutian aurkitu den zur bakarrak azken eraztuna 1494koa du, zurgizenez 18 eraztun ditu eta azkenerako eraztun gutxi falta zaizkionez patio txikiko dataziorekin bat egin da. Izan ere egitura arkitektoniko antzekoa baitute.

\subsubsection{0-1511 fasea}

Lehenik, 13 barrutian zazpi soliboen zurak aztertu dira, hauetatik hiruk azken urtea dute eta hain zuzen ere 1510-1511 urtean ebakiak izan ziren. Beste solibo baten zurak ez du ebaketa urterik eta beste bat ezin izan da datatu. 
Bigarrenik, arku punta duen ate nagusiak (armarria duena) tranka horman gordetzeko duen zura lagindu ahal izan da, eta azken eraztunaren data 1491koa da, hainbat eraztun falta zaizkio. Aurreko egiturekin duen erlazioa eta zurgizena aztertuaz, falta diren hauek 20 direla estimatu da.

\subsubsection{3-1564 fasea. Zumarra}

Urte honetan 3. barrutiko lehen solairuko frontalak egiteko erabili ziren zuhaitzak moztu ziren, zumarrak direnak alegia. Frontal hauek beheko ertzak landuak dituzte mutur batetik besteraino. Landutako forma hauek, bi zentimetroko diametroa duten forma zilindrikoak dira. Zur hauek, ere, frontal arteko ganga egiteko koska egina dute.

\subsection{8. $1566-1567$}

Zumar bat aurkitu da azken data honekin, hain zuzen ere 16. barrutitik 14. barrutira doan bat. Baliteke eskura zuten zur bat jarri izana.

\subsubsection{3-1584 fasea}

Ikertzailea iritsi aurretik langileek $\mathbf{1 6}$ barrutitik zur guztiak beste leku batera eraman zituzten. Langileek sortutako pilako zuretako bik azken eraztuna urte honetan dute eta azkenik ez duten beste bost zuren datazioa estimatua bat dator data honekin.

\subsubsection{8-1589 fasea}

Planoko 12 zenbakiarekin izendatutako barrutian 11 laginetatik bederatzik azken urtea 1588koa dute.

\subsubsection{XVII lehen laurdeneko fasea}

Fase honetako zurei azken eraztuna falta zaie, beraz, datazioa estimatuko da eta akats tarte handiagoa izango du. Hain zuzen ere fase honetakoak dira 9 barrutiko ateburua, $\mathbf{7}$ barrutian aurkitu zen ohol bakarra, eta, 6B barrutian aurkitutako 3 solibo. Aieru gisa, konponketa txikien fasetzat jo daiteke.

Planoko 6B barrutian hiru solibo laginduak izan dira, hirurak eraztun gutxikoak eta zurgizenik gabekoak. Gainera, 6Ako soliboek ez bezala bobeda egiteko koska landua dute. Alde honetan sute baten arrasto nabarmenak daude, pareta-harri gorrituak eta pareta belztua ikus daiteke. Aieru gisa, sute baten ondorioz alde hau berritua izan zitekeen.

\subsubsection{XVIII. mende bukaera eta XIX mende hasiera}

Teilatuko lata izena duten zortzi ohol aztertu dira. Ohol hauei azken urtea falta zaie eta gehienetan ez dute zurgizenik. Gauzak honela denbora tarte zabalagoa eman beharrean aurkitzen gara. Ebaketa urtea ez den azken eraztuna fase honetakoa aurkezten dute. Ekialdeko paretako leihoetako zurak ere XIX mende hasierakoak dira. Baita ere, 6A barrutiko arkua duen ateak zuen markoa garai honetakoa da. 13 barrutiko frontal bat ez erortzeko jarritako mentsula, ekialdeko paretan, garai honetakoa da ere.

Garai honetan teilatua konpondu zela antzematen da eta hainbat zurezko leiho egin ziren, beste konponketa txikiren artean.

Zuren azterketak ez digu erakutsi garai honen ondorengo zurik. Honek ez du esan nahi baten bat konponketa gisa ondoren jarria izan ez denik.

\section{EZTABAIDA}

Dendroarkeologian lanean ari garela garbi izan behar dugu ematen diren datak zuhaitzaren ebaketarenak direla. Bestalde, garbi izan behar da ere zurak elkartua duen harrizko eraikina lehenagokoa ala geroagokoa izan daitekeela, lehen kasuan zegoen eraikin bat eraberritzeko erabili direlako, hau da, konponketa bat egin zaio eraikinari. Eta bigarren kasuan zurak bi edo erabilera gehiago izan dituelako, hau da, beste zaharragoa den eraikin batetik ekarria izan delako. Zehaztasun gabezia hau murrizteko lagin tamaina handitzea da dagoen tresnetako bat. Jauregizaharraren kasuan 242 zur desberdin aztertu direlarik uste da ziurtasun handia lortu dela emandako datekin eta, beraz, aintzat hartzekoak direla hemen emandako datak eraikinaren datekin alderatzen direnean.

Nafarroan eta Espainia iparraldean garaikideak diren antzeko jauregi asko dago, eta, zuhurtziaz jokatu behar da jauregi baten xehetasun handiko datazio batek besteekiko ematen duen informazioari buruz hitz egiterakoan. Beste jauregietan ikerketarik bideratu gabe ezingo ditugu Jauregizaharrean lortu diren datak beste jauregietara arinki zabaldu.

\section{ESKER ONAK}

Aranzadi Zientzia Elkarteari zurak lagintzen uzteagatik eta laginketen gastuak bere gain hartzeagatik. Esker onak ere eman nahi dizkiot artikulua ebaluatu duten zientzialari itsuei beraien zuzenketak direla medio.

\section{ERREFERENTZIAK}

Bunn, A.G., 2008. A dendrochronology program library in R (dplR). Dendrochronologia, 26(2), pp.115-124. Available at: http:// linkinghub.elsevier.com/retrieve/pii/S1125786508000350 [Accessed July 12, 2017].

Bunn, A.G., 2010. Statistical and visual crossdating in $R$ using the dpIR library. Dendrochronologia, 28(4), 251-258. Available at: http://linkinghub.elsevier.com/retrieve/pii/S1125786510000172 [Accessed July 12, 2017].

Cook, E.R., Kairiukstis, L.A., 1990. Methods of Dendrochronology, Springer, London. 
Grissino-Mayer, H.D., 2001. Evaluating crossdating accuracy: A manual and tutorial for the computer program COFECHA. Tree-Ring Research 57, 205-221.

Holmes, R.L., 1983. Computer-assisted quality control in treering dating and measurement. Tree-ring Bulletin 43, 69-78.

Knibbe, B., 2000. On Screen Measuring and Image Manipulation-OSM. Available at: http://www.sciem.com/download/.

Lizeaga Rica, J., 2009. Estudio de las maderas halladas en Andelo. Trabajos de arqueología Navarra 21, 287-292. Available at: https://dialnet.unirioja.es/descarga/articulo/3126839.pdf.

Lizeaga Rica, J., 2010. Datación de maderas muestreadas en la Casa de Condestable. Trabajos de arqueología Navarra 22, 249-260. Available at: https://dialnet.unirioja.es/descarga/articulo/3367489.pdf.

Schoch, W., Heller, I., Schweingruber, F.H., Kienast, F., 2004. Wood anatomy of central European Species. Available at: www.woodanatomy.ch.

Sherwin, C., 1988. Comparative Wood Anatomy, Springer-Verlag, Berlin.
Susperregi Lasalde, J., Prado Alvarez, S., 2000. La dendrocronología: definición y breve historia. Boletín Arkeolan 9, 8-13.

Susperregi Lasalde, J., Prado Alvarez, S., 2003. Dendrocronología del roble en Gipuzkoa: análisis climático a partir de las series de crecimiento. Boletín Arkeolan 11, 127-184.

Susperregi Lasalde, J., 2004. Nueva extensión cronológica de la curva de referencia dendrocronológica de Arkeolan (s. XIVXXI) y ampliación del marco geográfico de aplicación de la misma. Boletín Arkeolan 12, 159-168.

Susperregi Lasalde, J., 2016. Análisis dendrocronológico de la cubierta de la Iglesia de San Pedro de Bergara. Boletín Arkeolan 18, 239-250.

Susperregi Lasalde, J. et al., 2017. The Basque farmhouses of Zelaa and Maiz Goena: New dendrochronology-based findings about the evolution of the built heritage in the northern Iberian Peninsula. Journal of Archaeological Science: Reports 11, 695-708. Available at: http://www.sciencedirect.com/ science/article/pii/S2352409X16306186. 
